
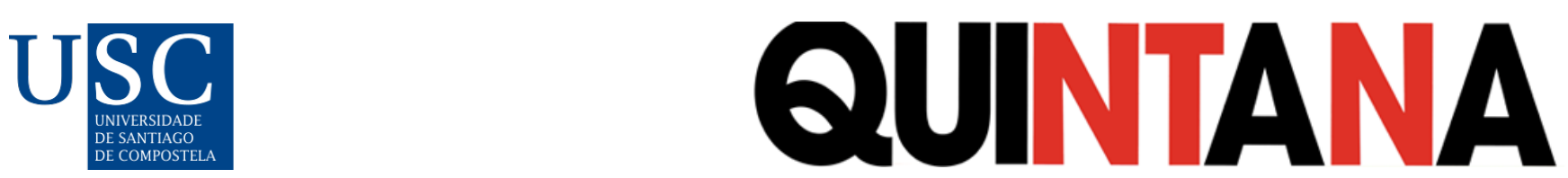

Quintana: revista do Departamento de Historia da Arte, (20), 2021. ISSN-e: 2340-0005

https://doi.org/10.15304/quintana.20.7657

\title{
Semejanzas, afinidades, correspondencias. Relaciones del cine con las artes visuales y la música. Jorge Oter, Imanol Zumalde y Santos Zunzunegui, Universidad del País Vasco / Euskal Herriko Unibertsitatea, Bilbao, 2020. 172 págs. ISBN: 978-84-1319-292-5
}

\author{
Daniel González Coves $^{1}$ (iD \\ ${ }^{1}$ Universidad Complutense de Madrid, España
}

Como afirma Imanol Zumalde en su introducción a los distintos textos que forman parte de este volumen, el cine ha tenido una estrecha relación con los distintos medios visuales que lo precedieron y también con la música desde sus inicios en las primeras décadas del siglo XX. El estudio de la mutación que representa el paso de la imagen fija a la imagen cinematográfica, y las intersecciones entre lo visual y lo auditivo, motiva esta publicación; dos tipos de estímulos sensoriales diferenciados en cuanto a su naturaleza que, sin embargo, la producción cinematográfica logra aunar para generar un contenido nuevo. Entre los distintos capítulos se muestran, desde múltiples perspectivas, acercamientos a este fenómeno que, por otra parte, ofrece un terreno de estudio fértil tras más de un siglo de convergencia entre estas dos disciplinas artísticas. Además, se analizan las consecuencias de la introducción de esta tecnología - que permite fijar el movimiento y después reproducirlo en su duración- para una generación de autores que, viniendo de la imagen fija, exploró sus posibilidades como un nuevo elemento de creación visual.

La publicación, promovida por el grupo de investigación Mutaciones del Audiovisual Contemporáneo (MAC), es fruto de dos cursos realizados en 2016 y 2017 en el marco de los Cursos de verano de la Universidad del País Vasco (UPV/EHU) en los cuales se abordó el contacto entre diversos sistemas de expresión: cine, pintura y fotografía, en un primer encuentro, y un año después centrando su atención en la presencia de la música en el cine mediante la aportación de distintos puntos de vista de los autores y sus respectivos campos de estudio. De este modo, el libro se presenta como un conjunto de textos derivados de las ponencias que tuvieron lugar en aquellas presentaciones académicas, con la intención de no ser meras transcripciones de los distintos puntos de vista expuestos sino como un material resultante del mismo que sea empleado por el lector con el objetivo de ser el punto de partida de nuevas investigaciones sobre esta temática.

El prólogo, realizado por Jorge Oter y Santos Zunzunegui, plantea la práctica artística en sus distintas expresiones como territorios permeables cuyas ambiguas fronteras presentan características vaporosas y móviles. Las distintas disciplinas se nutren unas de otras generando parentescos y afinidades y, de este modo, los artistas buscan y encuentran en otras disciplinas 
soluciones, aparentemente ajenas a su medio, para asimilarlas e incluirlas de un modo orgánico en sus producciones. Como los propios autores afirman, los artistas encuentran en otros medios "claves creativas ignoradas, «confrontaciones» a partir de las que Souriau reconoce una interiorización en el «conocimiento profundo de su propia actividad»" (p.15).

Josep M . Català plantea la imagen cinematográfica como un tipo de producción artística que a lo largo de su existencia ha dialogado con las demás disciplinas artísticas para paulatinamente emerger como un medio original que logra trascenderlas mediante la asimilación de las distintas características de las mismas en un único proceder, ya que sus propiedades tecnológicas le permiten adaptar y desarrollar el potencial de las artes del espacio y el tiempo precedentes. Sin embargo, este autor propone dos tipos de relaciones entre el cine y las demás artes: uno de tipo mecanicista, más superficial, y otro más profundo, en el cual el procedimiento propio de otras artes ha sido asimilado por el cine que lo reproduce, tras haber sido digeridas sus propiedades, de un modo orgánico. En la búsqueda de estas relaciones entre artes de tipo más profundo, implícito o tácito, Català propone la obra de Orson Welles - y en concreto el film Ciudadano Kane (Citizen Kane, 1941) - como pionera en introducir problemas del ámbito de lo teatral en la imagen cinematográfica. En esta película, el espacio y la función de la escena desarrollan los fundamentos de un tipo de escenografía de naturaleza cinematográfica que parte de una asimilación de las características estructurales de la estética teatral. En este sentido, el autor plantea que una relación de tipo mecanicista consistiría en copiar los rasgos característicos más superficiales sin profundizar en la esencia del medio. El planteamiento de Welles, sin embargo, consiste en alejarse de la anécdota para utilizar elementos propios de lo teatral y reproducirlos en un medio distinto como lo es el cine. Otros ejemplos de estas relaciones entre artes son propuestos por este autor, en este caso entre la pintura y el cine con el trabajo del director de fotografía Vittorio Storaro. Su producción, que se encuentra en el marco de la imagen cinematográfica, plantea un estilo propio basado en el estudio de la iluminación utilizada por diversos artistas en el medio pictórico para posteriormente aplicar sus cualidades internas en la imagen cinematográfica. De este modo, esto no consiste en la creación de un tipo de imagen cinematográfica utilizando motivos o referencias que puedan provocar en el espectador la sensación de lo pictórico en el cine, sino en el estudio concienzudo de la iluminación para poder extraer de ella su esencia y posteriormente expresar esto mediante herramientas estrictamente cinematográficas.

Català plantea también la existencia de un problema en la crítica cinematográfica actual, la cual divide y posteriormente evalúa por separado el proceso de producción cinematográfico en sus diversas facetas y los especialistas que en él intervienen, y que otorga además a la figura del director un papel principal que diluye la importancia del resto. Sin embargo, este autor defiende que esta separación de funciones entendidas como procesos aislados o autárquicos, relacionado además con el imaginario de los procesos de producción industrial, ensombrece "las decisiones que van tejiendo la amalgama orgánica finalmente concretada en las imágenes, al margen de las autorías particulares que firman cada uno de los niveles de la actividad fílmica" (p.38). Esta amalgama orgánica a la cual Català se refiere es la esencia de lo que denomina como la imagen-emoción, una maraña de decisiones tecno-estéticas que, en conjunto, conforman la totalidad fílmica y componen una determinada unidad visual emocional. En este sentido, componentes de este conjunto cinematográfico, tales como la excelencia actoral o cualquier otro elemento específico, sólo pueden funcionar de un modo efectivo cuando han sido correctamente asimilados y posteriormente adaptados mediante un proceso de transformación profundo que genere atmósferas visuales que se articulen para crear una emoción a través de un espacio filmado, algo que ha sido procesado para 
Semejanzas, afinidades, correspondencias. Relaciones del cine con las artes visuales y la música. Jorge Oter, Imanol Zumalde y Santos Zunzunegui, Universidad del País Vasco / Euskal Herriko Unibertsitatea, Bilbao, 2020. 172 págs. ISBN: 978-84-1319-292-5

regresar transformado emocionalmente. Las posibilidades que el medio cinematográfico ofrece, según este autor, pueden ser en este sentido sólo comparables a la música como medio que también se desarrolla en el tiempo, una plataforma emocional que del mismo modo que el cine, encadena emociones que se suceden en el tiempo aunque en este caso sólo con herramientas de naturaleza sonora.

Natalia Ruiz ofrece, por otra parte, un estudio sobre las incursiones de artistas procedentes de otros medios como la pintura en el ámbito de la producción cinematográfica y, por tanto, la inclusión de la temporalidad en su obra artística. Esta cualidad temporal atrae a los artistas contemporáneos a la experimentación y posterior difusión de esta tecnología, que utilizan como un medio expresivo con el cual desarrollar conceptos y problemáticas surgidas en sus propios medios. Así, artistas de las primeras vanguardias, como los cubistas y los futuristas, utilizan la imagen cinematográfica debido a su idoneidad para captar de una forma plástica el ritmo y la velocidad, conceptos que pueden encontrarse en sus producciones pictóricas: Fernand Léger y Dudley Murphy con Ballet mécanique (1924); Viking Eggeling con Symphonie diagonale (1924); Hans Richter con Rhythmus 21 (1921); Walter Ruttmann con sus Opus I-IV (1920-1923); Oskar Fischinger con sus trece Studie (1929-1934); Marcel Duchamp y Man Ray con Anémic cinéma (1926) y finalmente Entr 'acte (1924) rodada por René Clair en colaboración de Francis Picabia y el músico Erik Satie.

Cloe Masotta presenta en su capítulo un acercamiento a las distintas maneras que la producción visual previa al cine ha ingeniado para hacer manifiesta la huella del movimiento en la imagen fija y, por otra parte, la influencia que este tipo de soluciones, creadas en el marco de la pintura y la fotografía principalmente, han tenido en la imagen cinematográfica con posterioridad, en ocasiones creadas por los mismos artistas provenientes de la imagen fija en su experimentación cinematográfica. Como la propia autora recuerda, el cine contagia a las artes plásticas y del mismo modo, este tipo de imagen hace lo propio con el medio cinematográfico. Estas exploraciones visuales, resultado de la dificultad que supone representar el movimiento en un medio que no posee dicha cualidad, llevan a lo que Masotta denomina como arabescos y filigranas, resultado de la estela que el movimiento imprime en las imágenes fijas y que después fueron trasladados al cine como un recurso adicional en la experimentación cinematográfica del movimiento. La autora propone ejemplos concretos en el ámbito del cubismo, donde la multiplicación de perspectivas en una misma imagen genera un contenido difuso donde puede advertirse el desplazamiento de un elemento a través del espacio, y también la célebre pintura de Marcel Duchamp Desnudo bajando una escalera no 2, una sola imagen que representa una secuencia temporal donde en la repetición y superposición de elementos que tratan de sugerir ese movimiento puede advertirse el rastro de un cuerpo humano que se desplaza por una escalera, o las distintas representaciones de la bailarina Loïe Fuller que Henri de Toulouse-Lautrec y Giacomo Balla realizaron, donde cada uno, desde sus propios medios, tratan de traducir y representar el movimiento generado por la motricidad de la danza en el espacio, utilizando la litografía y la escultura como medios para simularlo.

Por otra parte, Santiago Martín Bermúdez realiza un minucioso repaso de la evolución de la composición musical en el marco de la producción cinematográfica de Hollywood en el siglo XX. En el texto se aborda la colaboración del músico Bernard Herrmann y el cineasta Alfred Hitchcock y también la producción musical de Erich Wolfgang Korngold y Max Steiner, dos autores de origen centroeuropeo cuyas composiciones ideadas para el cine suponen la creación de un modelo en el que posteriormente se basaron otros autores durante décadas en la producción musical en el marco del cine de Hollywood. Finalmente, se analiza también la obra de Henry Mancini como una puesta 
en cuestión del modelo anterior, y la mutación o evolución hacia un nuevo modelo posterior para la música del cine de masas.

Imanol Zumalde plantea además en esta publicación un estudio sobre el funcionamiento y estructura del género musical en el cine de Hollywood y los paralelismos que se pueden encontrar en algunos aspectos en cuanto a lo que significó el carnaval en tiempos pretéritos, en concreto el Medievo y el Renacimiento. El cine comercial de Hollywood está enfocado al entretenimiento y el ocio del espectador, características que se llevan al extremo en el género musical y acentúan este sentido lúdico. Como el propio autor señala, el cine americano trata de crear un contenido que aporte una visión alegre de la vida, distrayendo y evadiendo al espectador de su entorno, y es en el género musical donde esta finalidad se muestra de un modo más explícito, relajándose incluso la censura propia de las instituciones de la época en favor de un tono relajado y humorístico.

Asimismo, este autor argumenta acerca de la existencia de dos niveles diferenciados en la narración en este tipo de cine, siendo el primer nivel similar al que puede encontrarse en el cine narrativo convencional de Hollywood y en el que, entre otras características, se observa un tipo de escenificación en el cual los personajes parecen ignorar la existencia del espectador. Sin embargo, en el género musical se añade otro tipo distinto de escenificación en el que los personajes toman consciencia de su propia naturaleza ficcional y se dirigen directamente al público. Estos periodos funcionan como un paréntesis en el que las reglas del cine convencional son ignoradas o infringidas, y donde precisamente se incluyen las canciones y los bailes característicos del género. Además, es común en este tipo de cine la existencia de un cierre o desenlace apoteósico en el que esta dualidad se desvanece y la ensoñación que suponen los periodos musicales se impone sobre el tipo de narración más verosímil o fiel a una narración realista. Este segundo nivel que Zumalde observa en el género musical es el que precisamente le permite compararlo con el carnaval medieval, lo que el autor denomina como una especie de trance o éxtasis expiatorio que supone una abolición de las normas por un periodo temporal en el que emerge lo extravagante y se libera aquello que estaba reprimido. En el caso concreto del carnaval de la Edad Media y el Renacimiento, esto implicaba la interrupción de las normas regidas por las leyes del Estado y la Iglesia, además de la ruptura de las barreras de clase, estatus económico o sexo en favor de lo cómico, la burla e incluso la blasfemia.

Por último, Daniel V. Villamediana ofrece un repaso sobre el movimiento del Direct Cinema en el ámbito del documental musical o rockumentary y las distintas producciones que tuvieron lugar en lo que supuso su época más fecunda y reconocida, del año 1967 hasta el 1972. Como el propio autor señala, este cine se caracteriza por un tipo de filmación en el que se muestra a los personajes en su entorno cotidiano, aspirando por tanto a registrar y mostrar al público experiencias y momentos únicos en los cuales el propio creador de las imágenes no interviene para dirigir el contenido o el curso de los acontecimientos, y resaltando además esa sensación de aleatoriedad y realismo fidedigno con un estilo de grabación de apariencia descuidada, intuitiva o improvisada. Un tipo de rodaje casual en el que es posible apreciar en la imagen los propios movimientos del operador de la cámara, además de otras características como la utilización del zoom de un modo brusco, el sonido directo y la ausencia de voz en off. Este modo de proceder en el marco de la creación cinematográfica se valió de los nuevos avances tecnológicos para poder desarrollar este estilo visual, en el que se busca hacer sentir al espectador la experiencia presentando los hechos sin procesar y participar, en consecuencia, de forma directa en aquello vivido por los protagonistas. El punto de vista del operador es el punto de vista del espectador, al cual se le interpela para que experimente de un modo directo y realista el evento que está desarrollándose en las imágenes. Entre las películas pioneras de este género, el autor señala Don 't Look Back (1967), de D. A. Pennebaker; Gimme Shelter 
(1970), de Albert y David Maysles; Woodstock: 3 Days of Peace \& Music (1970), de Michael Wadleigh y finalmente Cocksucker Blues (1972) de Robert Frank.

Estamos ante una obra original que aporta un conjunto de planteamientos heterogéneos en cuanto la temática y estilos de sus autores y que, sin embargo, guardan un nexo común: las relaciones que la música, en sus múltiples expresiones, ha tenido con la imagen cinematográfica desde su invención en los inicios del siglo XX. Una temática que, lejos de mostrar signos de agotamiento, presenta un terreno fecundo con múltiples senderos aún inexplorados y que, del mismo modo que permite comprender con mayor profundidad el funcionamiento y naturaleza de la imagen cinematográfica, revitaliza las demás artes precedentes con nuevos modelos o patrones que las nuevas tecnologías introducen en la producción visual. 